\title{
A Case Study of Second Language Translation Competence of Chinese College Students
}

\author{
Fang Liu \\ College of Foreign Language \\ Tianjin Polytechnic University \\ Tianjin, China
}

\begin{abstract}
Translation competence has been defined in various ways over the years. This paper tends to observe students' competence of translating into a second language from the angle of target language competence, namely discourse or textual competence. A case that analyses the target texts of a group of non-English major sophomore students in Chinese university translating from Chinese into English as their second language is used in this paper to profile the textual component of Chinese college students' second language translation competence. After studying the case, we may hypothesize that the ability to translate into a second language develops in a systematic way. Target language competence is an important element of translation competence.
\end{abstract}

Keyword—translation competence; second language; textual competence

\section{INTRODUCTION}

Over the years, many scholars have attempted to describe the components of translation competence in various ways. The term translation competence is defined differently over the last thirty years.

During 1970s and 1980s several scholars viewed translation competence mainly from linguistic angles and do not pay much attention to how translators perform their job in the world. Later, some scholars (Krings, 1986; Pym, 2003; Shreve, 1997) suggest that there is one supercompetence above other linguistic subcompetences which is the competence through which the minimalist definitions of translation develop later. Pym believes that a minimalist definition of translation competence isolates the essence of translation from other variables and competences such as linguistics competence and world knowledge which is an advantage of this definition. As translation studies developed as an interdisciplinary field and several diverse activities are required in translation business and translation market, various components can be categorized under the label of translation competence. Multicomponential models employ research in second language acquisition and performance in linguistics (Pym, 2003). These models assume that translation competence is composed of an array of several linguistic and extralinguistic subcomponents.

Translation studies has only recently become translatorcentered, rather than centered on the target text or the languages themselves. This shift of perspective has run parallel to development in applied linguistics concerned with the study of bilingualism, contrastive analysis, interlanguage and second language acquisition. At the same time, translation studies has virtually ignored the reality of translation into the second language, a natural and commonly occurring activity. The problems of translating into a second language beg to be answered in an interlanguage framework.

A key argument of this paper is that one of the aspects of translation competence is competence in the target language, and specially at the level of text or discourse. That is to say part of learning to translate into a second language is learning to writing in a stylistically authentic way. In this paper, a case that analyses the target texts of a group of nonEnglish major sophomore students in Chinese university translating from Chinese into English as their second language is dealt with to describe textual competence. The aim is to profile the textual component of Chinese college students' second language translation competence. Bachamn defined textual competence like this. It includes the knowledge of the conventions for joining utterances together to form a text, which is essentially a unit of language-spoken or written-consisting of two or more utterances that are structured according to rules of cohesion and rhetorical organization (Bachman,1990:88).

The case study was based on the translation of 40 nonEnglish majored sophomore students for their final examination at the end of the fourth semester. The candidates were all native speakers of Chinese, and each translated the same passage, called here The United Nations' World Conference on Women, with 257 Chinese characters. Each translation was marked by two different teachers and the Spearman Rank Correlation is 0.841 . The Correlation is significant at the 0.01 level. All candidates were divided into four ability groups under the following criteria: they should be roughly equal in size and they should each comprise a cluster of grades with a fairly clear break between one group and the next "Table I".

TABLE I. ABILITY GROUPS OF THE CANDIDATES

\begin{tabular}{|l|l|l|}
\hline & Range of Scores & Number of candidates \\
\hline Group 1 & $0-15$ & 6 \\
Group 2 & $23-29$ & 9 \\
Group 3 & $32-37$ & 15 \\
Group 4 & $39-46$ & 10 \\
\hline
\end{tabular}


Nine analyses were chosen in an attempt to profile the competence of these students. There are: text length, type token ratio, tokens misspelt, average word length, words directly translated, words shifted, words omitted, verb noun ratio and content function words ratio. For the purpose of comparison, the results of the amylases are expressed as Zsores, rather than raw scores (If raw scores are needed, please contact the author).

\section{CASE STUDY}

\section{A. Text Length and Type Token Ratio}

Text Length and Type/Token Ratio Expressed as Z-Score: Positive Values in Text Length Indicate Longer Text and Positive Values In TTR Indicate More Varied Lexis. "Table II"

TABLE II. TEXT LENGTH AND TyPE TOKEN RATIO

\begin{tabular}{|l|l|l|}
\hline & Text Length & TTR \\
\hline Group 1 & -1.75 & -0.24 \\
Group 2 & 0.22 & -0.07 \\
Group 3 & 0.27 & -0.06 \\
Group 4 & 0.45 & 0.02 \\
\hline
\end{tabular}

Text length would reflect two facets of translation competence. First, very poor translators would produce shorter text because they would omit to translate difficult parts. Secondly, English is hypotactic while Chinese is mainly paratactic, when translating from Chinese to English better students may notice this difference and add cohesive ties like relatives, connective and prepositions to realize overt coherence of English. So good students' translation seem to have more words than mediocre students.

In a composition task, high type/token ratio (ttr) can be interpreted as a rich lexical repertoire, because the author composes freely on topic. But in a translation task, type/toke ratio can only be increased by giving several alternatives for the same source text term or by decreasing the proportion of function words (with their limited number of types) and increasing the proportion of content words (which may be if a great number). So in this case a high type/toke ratio can show the students' ability to use multiple equivalents and/or the ability to write dense text by using lexicalizations. Type/token ratio of the poor and mediocre groups were similar, while in the good group it was much higher (Type/token ratio were calculated by Powercon software).

\section{B. Average Word Length and Words Misspelt}

Average Word Length And Words Misspelt Expressed As Z-Score: Positive Values In And Positive Values In Average Word Length Indicate Longer Words. Positive Values In Word Misspelt Indicate Poorer Spelling. "Table III"

Average word length may reflect two factors: a higher score reflect a lower proportion of function words, which are generally short words in English; and among content words it reflects longer and more complex words. Poor group has the lowest average word length and the good group has the highest. The explanation for lower mediocre higher than higher mediocre group is that the relatively poorer group omitted function words because of their lack of syntactic ability.

TABLE III. AVERAGE Word LENGTH AND WordS MisSPElT

\begin{tabular}{|l|l|l|}
\hline & Average word length & Words misspelt \\
\hline Group 1 & -1.71 & 1.20 \\
Group 2 & 0.21 & 0.04 \\
Group 3 & 0.18 & -0.01 \\
Group 4 & 0.42 & -0.61 \\
\hline
\end{tabular}

Words misspelt reflect written language competence of the four ability groups. As was predicted, the poor group has most misspelling the good group has the least.

\section{C. words directly translated, words shifted and words omitted}

Words directly translated, words shifted and words omitted expressed as Z-scores: positive values indicate more direct translation, more shifts of grammatical category and more source words not translated. Negative values indicate less direct translation, less shifts and less source words not translated. "Table IV"

TABLE IV. WORdS Directly Translated, WordS ShIFTED AND WORDS OMITTED

\begin{tabular}{|c|c|c|c|}
\hline & Directly translated & Shifted & Omitted \\
\hline Group 1 & -1.80 & -1.20 & 2.13 \\
Group 2 & 0.49 & 0.06 & 0.45 \\
Group 3 & -0.29 & 0.17 & -0.33 \\
Group 4 & -0.22 & 0.41 & -0.38 \\
\hline
\end{tabular}

Words directly translated, shifted and omitted were calculated by hand on a random sample of 20 source text words.

The words directly translated may reflect the extent to which students adhered to the lexical structure of the source text. Did they try to maintain the match between a source text word and its meaning, or were they prepared to distribute the meaning of a source text word over several words in target texts? Students in the poor group have the lowest score. They omit or radically recast the source text meaning because of their poor productive skills. The mediocre students play safe with translations that stick close to the source text, so they have the highest score. Students in good group are prepared to redistribute source text meaning over target text word boundaries.

Words shifted show the extent to which students were prepared to change the syntactic structure of source text. Words shifted mean words have undergone a shift in their grammatical category during translation. The poor group has the lowest score and the scores increase from mediocre group to good group. This seems to prove an increasing ability to manipulate the syntax of the target language.

The words omitted reflect the fullness of the translation relative to the source text by counting the number of source 
words for which there appears to be no direct or indirect equivalent in the target text. The poor group has most omissions, reflecting gaps in target language lexical repertoire, while the three higher group have rather few.

\section{Verbal/Nominal ratio and Content/Function Words}

Verbal/nominal ratio and content/function words expressed as Z-scores: positive values indicate more "verby" style and more content word words. Negative values indicate less "verby" style and more function words. "Table V"

TABLE V. VERBAL/NOMINAL RATIO AND CONTENT/FUNCTION WORDS

\begin{tabular}{|c|c|c|}
\hline & Verb/nominal ratio & Content/function words \\
\hline Group 1 & 0.65 & 0.35 \\
Group 2 & -0.10 & 0.06 \\
Group 3 & -0.36 & 0.17 \\
Group 4 & -1.70 & -0.14 \\
\hline
\end{tabular}

Verb/nominal ratio measures the content to which candidates adopted a more "verby" style in their translation, since the source text was highly nominal, the extent to which why had depart from the source text structure. The verbal/nominal ratio was calculated by dividing the number of verbs by the number of nouns. Quantifiers, pronouns and nouns used adjectively were not counted as nouns. Gerunds were counted as nouns. As for verbs, the entire complex, including modals and auxiliaries, was counted as a single verb, as were discontinuous verbal complex (for example, can never have). As the scores of the students' translation increase, they present less "verby" style, which indicate they are able to use nominalizations.

The content/function words analysis reflects the extent to which students rely on lexicalization as opposed to function words. The poor group has the highest score. They produced telegraphic text that lacked function words because of their poor second language ability. Mediocre students produces syntactically smooth text. So the scores tend to be lower. It is interesting to find the best students have the lowest score in content/function ratio. The best explanation of this lies in the differences between Hypotaxis in English and Parataxis in Chinese. Chinese has less functional words than English. According to Colina (1999), translators of higher levels was less influenced by the structure of the source language. Group 4 students have the awareness of the differences between two language and try to translate in a more nativespeaker-like way.

\section{CONCLUSION}

"Table VI" has grouped the analyses that give a broad picture of textual and general langue competence. The fist five items indicate textual competence and the last three generalize language competence. Some of the criteria are renamed to reflect favored choice. Average word length becomes longer words, more verbs has its sign revered and becomes more nominal, content/function words becomes more content words, more direct translations is reversed in sign and becomes more indirect translation, and words shifted becomes more grammatical shifts. Words misspelt has its sign reversed and becomes accurate spelling, words omitted is also reversed to become text fully translated and lexical variety becomes more varied vocabulary.

TABLE VI

\begin{tabular}{|l|l|l|l|l|}
\hline & Group 1 & Group2 & Group3 & Group4 \\
\hline Longer words & -1.71 & 0.21 & 0.18 & 0.42 \\
More nominal & -0.65 & 0.10 & 0.36 & 1.70 \\
More content words & 0.35 & 0.06 & 0.17 & -0.14 \\
More indirect translation & 1.80 & -0.49 & 0.29 & 0.22 \\
More grammatical shifts & -1.20 & 0.06 & 0.17 & 0.41 \\
Accurate spelling & -1.20 & -0.04 & 0.01 & 0.61 \\
Text fully translated & -2.13 & -0.45 & 0.33 & 0.38 \\
More varied vocabulary & -0.24 & -0.07 & -0.06 & 0.02 \\
\hline
\end{tabular}

Group 1 represented substandard competence. Group 2 and some students in group 3 presented pretextual competence. For this level, English competence is as yet bounded by sentence - the effort of constructing a wellformed sentence from whatever components come to hand demands all their powers. The upper limits of Group 3 and group 4 represented textual competence.

Students with substandard competence always have inaccurate spelling. Source text is not fully translated and their target texts are always short. Function words are often omitted so their target texts contain high proportion of content words. Their translation is rather indirect because of efforts to deal with poor target language repertoire. Pretexual level students have more accurate spelling. Source text is fully translated. Target texts are long and strung-out because of the use of function words rather than lexicalizations. Their vocabulary is not varied. Their translation is structurally very close to the source text and style is more 'verby'. Textual level students have accurate spelling. Target texts are long and syntactically dense through the use of lexicalizations. Style is more nominal and words are longer and more varied. Their target texts are structurally more distant from the source text because of grammatical shifts and indirect translation of source text words.

This research tends to show the fruitfulness if an interlanguage/second language acquisition approach to second language translation. By using of textual competence as a medium, it is possible to hypothesize that the ability to translate into a second language develops in a systematic way. Target language competence is an important element of translation competence. It particularly points to the fact that translators into the second language exhibit a range of ability in deploying language at the level of the text. Much translation assessment operates by describing the deficiencies of the target language text, we can now propose a method that describes the competence of the producer of the text.

\section{REFERENCES}

[1] Bachman L F. Fundamental Consideration in Language Testing [M] Oxford: Oxford University Press, 1990:88. 
[2] Chen, M, \& SZechnerm k. Computing and evaluating syntactic complexity features for automated scoring of spontaneous non-native speech [A]. In Proceedings of the $49^{\text {th }}$ Annual Meeting of the Association for Computational Linguistics [C], 2011.

[3] Colina. S. Transfer and unwarranted transcoding in the acquisition of translational competence. An empirical investigation [A]. InV. Jeroen (ed) Translation and the (Re)location of Meaning [C]. Selected papers of the CERA Research Seminars in Translation Studies Leuven, 1999,35-391.

[4] House, J. A. 2001. Translation quality assessment: Linguistic description versus social evaluation [J]. Meta, 46(2):243-57

[5] Krings, H.P. (1986). Translation problems and translation strategies of advanced German learners of French. In J. House, \& S. BlumKulka (Eds.), Interlingual and intercultural communication (pp. 26375). Tubingen: Gunter Narr.

[6] Pym, 2003. Redefining translation competence in an electronic age. In defense of a minimalist approach. Meta XLVIII.4:481-497.

[7] Shreve G. 1997. Cognition and evolution of translation competence [A], In J. Danks el al. (eds.). 1997,120-136.

[8] Xiao, R. 2010. Using Corpora in Contrastive and Translation Studies [C]. New Castle Upon Tune: Cambridge Scholars. 